\title{
Cooperative Effects Involved in Esterolytic Reactions of Cationic Long Chain Esters Catalyzed by Benzimidazole-Containing Polymers
}

\author{
C. G. OVerberger ${ }^{1}$ and C. J. PodSIAdLY ${ }^{2}$ \\ Department of Chemistry and the Macromolecular Research Center, \\ The University of Michigan, Ann Arbor, Michigan 48104
}

Received March 1, 1973

\begin{abstract}
The solvolyses of positively charged esters with varying chain length catalyzed by benzimidazole, poly[5(6)-vinylbenzimidazole] and copolymers of 5(6)-vinylbenzimidazole with acrylic acid were studied. Poly[5(6)-vinylbenzimidazole] showed a marked selectivity for the positively charged esters with varying aliphatic chain length but the catalytic activity was suppressed. In order to investigate the more detailed characteristics of the 5(6)-vinylbenzimidazole-acrylic acid copolymers in the solvolyses of these esters, the effects of copolymer composition on their catalytic activities were studied. In the solvolyses of every ester employed, the copolymer compositions affected their catalytic activities. In 40\% 1-propanol-water the activities of the copolymers indicated a strong dependence on the carboxylatebenzimidazole-carboxylate triad. These effects were due to strong electrostatic interactions between these sequences and the substrates. The effects of solvent composition on the catalytic activities of the copolymer-catalyzed solvolyses were also investigated. The copolymers of 5(6)-vinylbenzimidazole with acrylic acid were found to have entirely different characteristics in methanol-water than in 1-propanol-water systems. The catalytic ability was found to be a function of the benzimidazole content and on the size of the substrate. Apolar interactions became a dominant force in the methanol-water system.
\end{abstract}

\section{INTRODUCTION}

Copolymers of imidazole with acrylic acid and vinylsulfonic acid have been utilized as catalysts in the solvolyses of neutral, negatively, and positively charged substrates $(1-3)$. The imidazole-acrylic acid copolymers were less effective catalysts than imidazole in the solvolyses of the neutral substrate, $p$-nitrophenyl acetate, and the negative substrate 4-acetoxy-3-nitrobenzoic acid, but showed a marked selectivity for the positive substrate, 3-acetoxy- $N$-trimethylanilinium iodide $\left(\mathrm{S}_{2}{ }^{+}\right)$at high $\mathrm{pH}$ values. A cooperative electrostatic interaction of the substrate with the carboxylate and neutral imidazole functions was reported. A dependence of the catalytic activity on the copolymer composition was also reported. In order to investigate further the contribution of apolar and electrostatic interactions for the macromolecule-substrate

\footnotetext{
${ }^{1}$ Present address: Department of Chemistry and the Macromolecular Research Center, The University of Michigan, Ann Arbor, MI 48104.

${ }^{2}$ Taken from the dissertation submitted by C. J. P. in partial fulfillment of the requirements for the degree of Doctor of Philosophy in the Graduate School of The University of Michigan. 
complex formation the solvolytic reactions of various positively charged long aliphatic chain esters catalyzed by poly [5(6)-vinylbenzimidazole] (relative to the catalytic activity of the monomeric analog, benzimidazole) and copolymers of 5(6)-vinylbenzimidazole with acrylic acid were investigated in different compositions of alcohol-water and at different $\mathrm{pH}$ values. It was of interest to investigate in more detail the characteristics of these reactions and to obtain further insight into the electrostatic and apolar interactions between charged substrates and charged pendant groups on the macromolecule. It was also of interest to investigate the effects of composition and monomeric sequence on the catalytic activities of poly[5(6)-vinylbenzimidazole] and of the 5(6)-vinylbenzimidazole-acrylic acid copolymers in the solvolyses of positively charged substrates of variable size and compare the results with those obtained for imidazole containing polymers (4). The benzimidazole unit is more hydrophobic than the imidazole group used in previous studies (4). Therefore, it was interesting to study how the increased hydrophobicity of the catalytic group would affect the catalytic behavior of the polymer and copolymers. Experimental difficulties due to lower solubility in water when compared with poly[4(5)-vinylimidazole] were recognized and this fact had a pronounced effect on the choice of solvent systems. It was also recognized that using solvent systems with less water would result in an experimental environment less conducive to hydrophobic bonding.

\section{RESULTS AND DISCUSSION}

\section{Copolymers of 5(6)-Vinylbenzimidazole with Acrylic Acid}

For the purpose of investigating the effects of copolymer composition on the catalytic activities of the copolymers of 5(6)-vinylbenzimidazole with acrylic acid (I), different compositions of the copolymers were prepared by varying the feed ratios of these monomers. The copolymerizations were performed at $75^{\circ} \mathrm{C}$ in absolute methanol using azobisisobutyronitrile (AIBN) as an intitiator. In every case, the copolymers

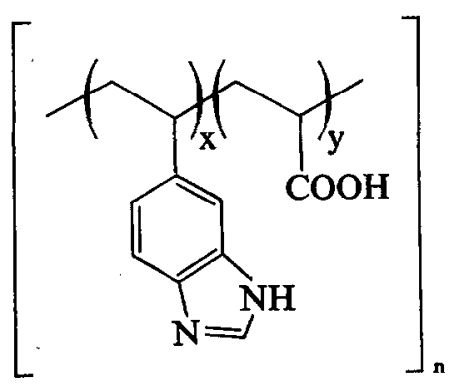

(1)

formed were insoluble in methanol and precipitated from the solvent during the course of the polymerization. The obtained polymers were purified by extensive dialysis in deionized water. The polymerization conditions and results are summarized in Table 1. 
TABLE $1^{a}$

RESULTS OF COPOLYMERIZATION OF 5(6)-VINYLBENZIMIDAZOLE WITH ACRYLIC ACD

\begin{tabular}{ccccc}
\hline \multicolumn{2}{c}{ Polymerization conditions } & \multicolumn{2}{c}{ Results } \\
\cline { 3 - 4 } $\begin{array}{c}\text { Feed } \\
\text { composition } \\
(\text { VBIm mole } \%)\end{array}$ & $\begin{array}{c}\text { Time } \\
(\mathrm{hr})\end{array}$ & $\begin{array}{c}\text { Conversion } \\
(\text { wt } \%)\end{array}$ & $\begin{array}{c}\text { Copolymer } \\
\text { composition } \\
(\text { VBIm mole } \%)\end{array}$ \\
\hline 20.0 & 1.25 & 35.4 & 35.4 \\
54.7 & 2.00 & 49.9 & 51.4 \\
97.1 & 3.00 & 39.9 & 66.1 \\
\hline
\end{tabular}

"AIBN as an initiator, in methanol, at $75^{\circ} \mathrm{C}$, with stirring during polymerization.

${ }^{b}$ Calculated from nitrogen content.

Based on previous results $(2,3)$, it was assumed that this copolymerization system has a strong alternating tendency. This is expected from the combination of vinyl monomers, one of which contains a strongly electron-withdrawing carboxyl group and the other a strongly electron-donating benzimidazole group.

\section{Solvolyses}

The catalytic activities for benzimidazole, poly-[5(6)-vinylbenzimidazole] and copolymers of 5(6)-vinylbenzimidazole with acrylic acid were investigated for the solvolyses of positively charged esters with varying aliphatic chain lengths (II).<smiles>[R]C(=O)Oc1cccc([N+](C)(C)C)c1</smiles>

(II)

$$
\begin{aligned}
& \mathrm{S}_{2}{ }^{+}, \mathrm{R}=\mathrm{CH}_{3}- \\
& \mathrm{S}_{7}{ }^{+}, \mathrm{R}=\mathrm{CH}_{3}-\left(\mathrm{CH}_{2}\right)_{5} \\
& \mathrm{~S}_{12}{ }^{+}, \mathrm{R}=\mathrm{CH}_{3}-\left(\mathrm{CH}_{2}\right)_{10}- \\
& \mathrm{S}_{18}{ }^{+}, \mathrm{R}=\mathrm{CH}_{3}-\left(\mathrm{CH}_{2}\right)_{16}
\end{aligned}
$$

Buffered 40\% 1-propanol-water, $40 \%$ methanol-water, and 30\% methanol-water were used as solvents throughout this study. Table 2 contains the catalytic rate constants for the $40 \%$ 1-propanol-water system.

It was believed that by using positively charged substrates and higher $\mathrm{pH}$ values the electrostatic effect which was observed in the previous experiments (5) would now increase the catalytic efficiency of poly[5(6)-vinylbenzimidazole]. The use of various long chained ester may also show further enhancements due to a supportive apolar effect.

In Table 2 we have the appearance of negative catalytic rate constants. This is due to the fact that at certain compositions the blank reaction was much faster. These 
TABLE $2^{a}$

Catalytic Rate Constants of Benzimidazole, Poly-5(6)-vinylbenzimidazole and Benzimidazole-Acrylic Acid Copolymers with Positively Charged Long Aliphatic Chain. Substrates $k_{\text {cat }}$ (liters/mole min)

\begin{tabular}{rlrrrrr}
\hline pH & Substrate & BIm & PVBIm & CP-35 & CP-51 & CP-66 \\
\hline \multirow{2}{*}{9.90} & $\mathrm{~S}_{2}{ }^{+}$ & -3.4 & -1.9 & -9.3 & 43.2 & -7.8 \\
& $\mathrm{~S}_{7}{ }^{+}$ & 7.1 & -5.3 & -2.3 & -0.5 & 1.1 \\
& $\mathrm{~S}_{12}{ }^{+}$ & 8.7 & -8.3 & -1.5 & -1.2 & -1.6 \\
& $\mathrm{~S}_{18}{ }^{+}$ & 5.1 & -2.2 & 1.3 & 0.3 & -1.0 \\
9.00 & $\mathrm{~S}_{2}{ }^{+}$ & 1.1 & 0.4 & 0.9 & 4.1 & -0.9 \\
& $\mathrm{~S}_{7}{ }^{+}$ & -0.1 & -0.3 & -0.2 & 0.6 & -0.9 \\
& $\mathrm{~S}_{12}{ }^{+}$ & 0.2 & 0.3 & -0.8 & -0.04 & -0.1 \\
& $\mathrm{~S}_{18}{ }^{+}$ & 2.1 & 0.9 & -0.4 & -0.3 & -0.1 \\
8.03 & $\mathrm{~S}_{2}{ }^{+}$ & - & - & 0.3 & 0.4 & 1.2 \\
& $\mathrm{~S}_{7}{ }^{+}$ & - & - & 0.2 & 0.3 & 0.4 \\
& $\mathrm{~S}_{12}{ }^{+}$ & - & - & 0.1 & 0.1 & 0.2 \\
& $\mathrm{~S}_{18}{ }^{+}$ & - & - & 0.02 & 0.4 & 0.7 \\
\hline
\end{tabular}

${ }^{a} 40 \% n \mathrm{PrOH} / \mathrm{H}_{2} \mathrm{O} ;[\mathrm{cat}]=5.0 \times 10^{-4} M ;[\mathrm{sub}]=5.0 \times 10^{-5} M ; \mu=0.02 ; T=26^{\circ} \mathrm{C}$.

negative values are used for comparative purposes and are actually a measure of inhibition of the blank rate of hydrolysis.

It was of interest to study this inhibition phenomenon because from the study of enzyme inhibitors, valuable information has been obtained on the substrate specificity, the nature of the functional groups at the active site, the mechanism, and the participation of certain functional groups in maintaining the specific conformation of the enzyme (6). Figure 1 shows the pH-rate profiles for benzimidazole and poly[5(6)vinylbenzimidazole] catalyzed solvolyses. For benzimidazole, increasing the $\mathrm{pH}$ causes an increase in the catalytic rate constants about $10 \times$ greater than that observed with the negatively charged substrates (5). This can be explained by the fact that at this $\mathrm{pH}$ there are substantial amounts of anionic benzimidazole groups which are much more nucleophilic than the neutral groups.

For poly[5(6)-vinylbenzimidazole], increasing the $\mathrm{pH}$ causes a decrease in the catalytic rate constants. This was not expected and indicates that this polymer exhibits a strong electrostatic attraction but the catalytic effect is suppressed. This polymeric effect can be seen better in Fig. 2 where the data for the effects on $k_{\text {eat }}$ by varying the

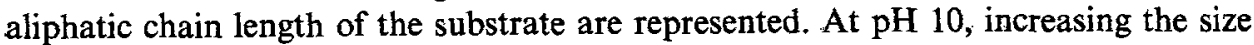
of the substrate causes an increase in the $k_{\text {cat }}$ for benzimidazole with a maximum around a 12 carbon chain length. This can be rationalized by the fact that initially for small substrates the electrostatic effect is very strong but decreases as the size of the substrate increases. When the size becomes very large, steric effects begin to slow the esterolytic reaction. For poly[5(6)-vinylbenzimidazole], the electrostatic effect is prominent throughout and increases with increasing size of the substrate, but as the chain becomes quite large this effect begins to diminish allowing the system to revert 


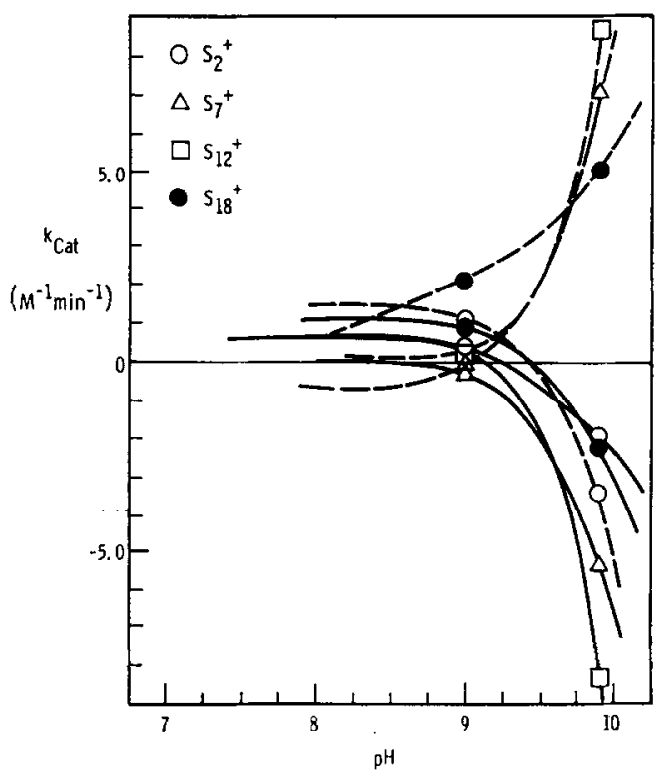

FIG. 1. pH-Rate profiles for the solvolyses of positively charged long aliphatic chain substrates catalyzed by benzimidazole (---), and poly-5(6)-vinylbenzimidazole $(-) .40 \% n \mathrm{PrOH} / \mathrm{H}_{2} \mathrm{O}$; $\mu=0.02$.

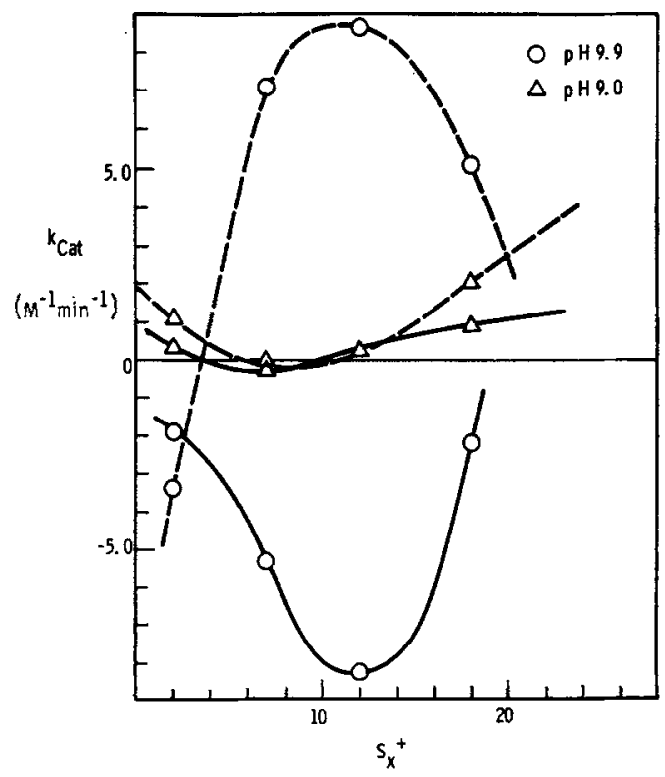

FIG. 2. Effect of varying chain length of positively charged esters on the catalytic rate constants for benzimidazole (--) and poly-5(6)-vinylbenzimidazole $(-)$ catalyzed solvolyses at various $\mathrm{pH}$. $40 \% n \mathrm{PrOH} / \mathrm{H}_{2} \mathrm{O}, \mu=0.02$. 
in the direction of normal blank hydrolysis. At $\mathrm{pH} 9.0$ both species exhibit similar effects.

A referee has considered an alternative suggestion. As shown by Fig. 2, both monomer and polymer result in essentially the same degree of negative catalysis for the small substrate $\mathrm{S}_{2}{ }^{1}$ at $\mathrm{pH} 9.9$, an indication that hydrophobic bonding is not important in this case as might be expected. However, the polymeric catalysis becomes more negative as one proceeds to larger, more hydrophobic substrates, $\mathrm{S}_{12}{ }^{+}$. The data tend to support a concept of the polymer forming a hydrophobic shield around the alkyl chain which, when of medium length, sterically blocks the attack of the carbonyl by another polymerically bound benzimidazole anion at $\mathrm{pH}$ 9.9. However, as one proceeds

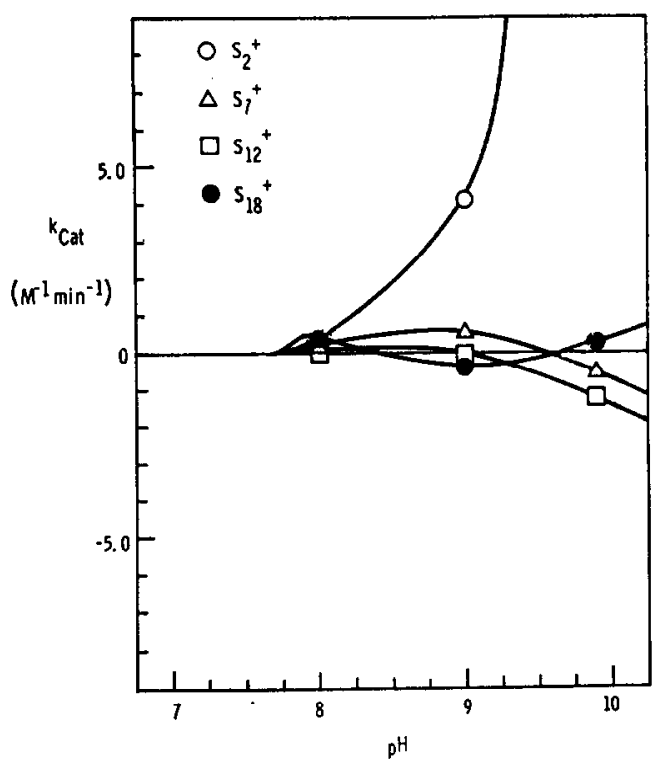

FIG. 3. pH-Rate profiles for the solvolyses of positively charged long aliphatic chain substrates catalyzed by the benzimidazole-acrylic acid copolymer ( $51 \mathrm{~mole} \% \mathrm{BIm}) .40 \% n \mathrm{PrOH} / \mathrm{H}_{2} \mathrm{O}, \mu=0.02$.

to even longer alkyl chains, $\mathrm{S}_{\mathbf{1 8}}{ }^{+}$, the rate again increases, indicating that the carbonyl function is now farther removed from the polymeric shield. This is an interesting suggestion which cannot be discounted.

If the monomeric benzimidazole is a catalytically active compound, why then is poly[5(6)-vinylbenzimidazole] a catalytically inactive binding species? This could be due to some conformational effect which occurs when the benzimidazoles are brought closer together, possibly through intramolecular $\mathrm{H}$-bonds. If this is the case, then dispersion of the benzimidazole groups, through copolymerization with a monomer which could act as a binding site, should increase the catalytic activity of the polymer.

The results of the hydrolysis of various positively charged esters by copolymers of 5(6)-vinylbenzimidazole with acrylic acid are presented in Table 2. The $\mathrm{pH}$-rate profile for CP-51 (51 mole \% BIm in the copolymer), which was the most catalytically active copolymer, is shown in Fig. 3. In general, this copolymer shows very little change in 
$k_{\text {cat }}$ for the large substrates with increasing $\mathrm{pH}$. For $\mathrm{S}_{2}{ }^{+}$we have a substantial increase in $k_{\text {cat }}$ with the value for $\mathrm{pH} 10$ off the graph.

In an attempt to find some pattern for catalytic rate vs variation in chain length, the desired plots were made. The data for CP-35 and CP-66 are quite similar to those obtained for poly[5(6)-vinylbenzimidazole]. On the contrary, the data for CP-51 (Fig. 4) show a pattern which has occurred consistently in the other solvent systems.

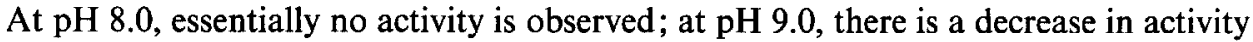
with an increase in size of the substrate; and at $\mathrm{pH} 10$ we have the so-called "smile" curve which indicates that some sort of steric effect operates where catalytic activity

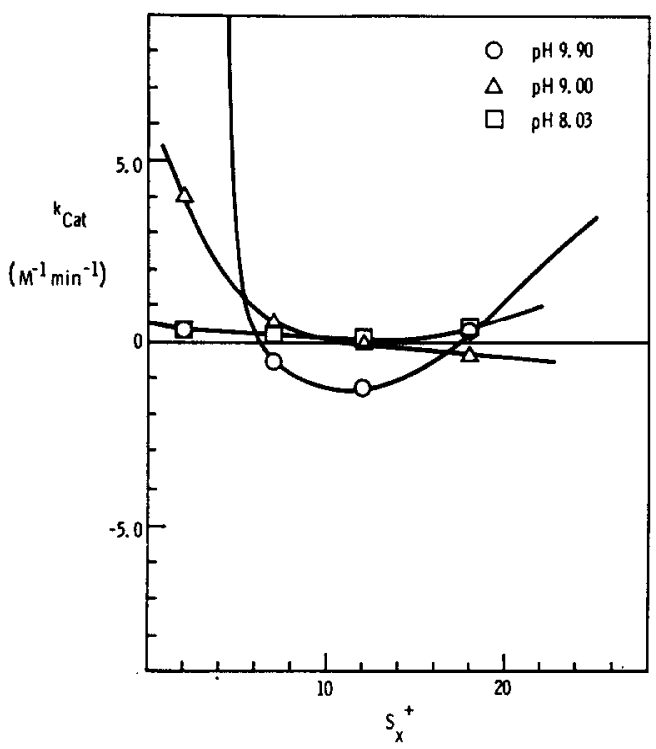

FIG. 4. Effect of varying chain length of positively charged esters on the catalytic rate constant for the benzimidazole-acrylic acid copolymer ( $51 \mathrm{~mole} \% \mathrm{BIm}$ ) catalyzed solvolyses at various $\mathrm{pH}$. $40 \% n \mathrm{PrOH} / \mathrm{H}_{2} \mathrm{O} ; \mu=0.02$.

is apparent. The steric effect could be caused by the destabilization of the transition state or by the decreased concentration in the polymer domain due to the size of the substrate.

The catalytic activities of the copolymers having different compositions followed bell-shaped curves showing maxima in the composition range of 45 to $55 \mathrm{~mole} \%$ in benzimidazole at an ionic strength of 0.02 (Fig. 5). For all the large substrates we essentially have very little change in the catalytic activity. On the other hand, for $\mathrm{S}_{2}^{+}$, we have a curve that is identical with the results obtained for this same substrate catalyzed by copolymers of 4(5)-vinylimidazole and acrylic acid in $30 \%$ ethanolwater $(2,3)$. The data represented here indicate that poly[5(6)-vinylbenzimidazole] is an inhibitor and as we decrease the benzimidazole content there is a narrow range where catalytic activity occurs. The $\mathrm{p} K$ for the acid moiety is 4.0 and therefore should show substantial ionization at the $\mathrm{pH}$ values investigated. The $\mathrm{p} K$ for the benzimidazole moiety in poly[5(6)-vinylbenzimidazole] is 4.5 and therefore should also show substantial ionization at $\mathrm{pH} 10$. The $\mathrm{p} K$ values for the copolymers are around 7.0 and 
therefore the benzimidazole moieties should be predominantly in the neutral form. A copolymer with a composition in the range of 45 to 55 mole \% benzimidazole content represents the ideal conditions of an anionic site, due to the carboxylate, and a catalytic site, due to a neutral isolated benzimidazole moiety. The negative deviation for the copolymer of benzimidazole content 35 mole \% at each. pH appears to be caused by an inhibitory effect associated with long acrylic acid sequences. A similar effect was

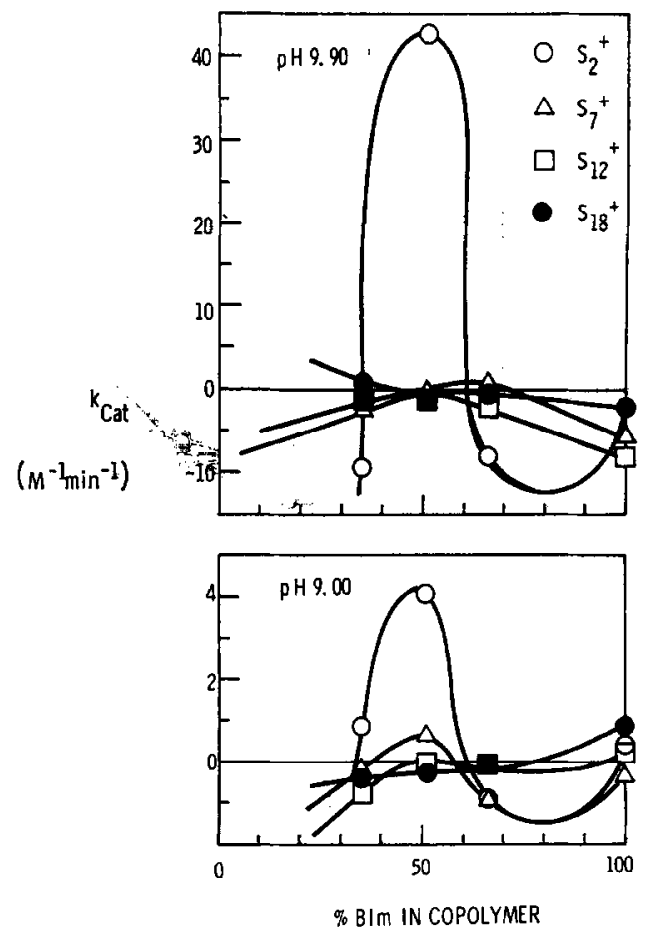

FIG. 5. Effects of copolymer composition on the catalytic rate constants for the benzimidazoleacrylic acid copolymer catalyzed solvolyses of the long chain positively charged substrates. $40 \%$ $n \mathrm{PrOH} / \mathrm{H}_{2} \mathrm{O} ; \mu=0.02$.

reported by Morawetz and Shafer (7) for the hydrolysis of the positively charged phenyl esters in the presence of polyanions and was also observed for 3-acetoxy- $N$ trimethylanilinium iodide $\left(\mathrm{S}_{2}{ }^{+}\right)$in the presence of polyacrylic acid. The positive deviation for the copolymer containing $66 \mathrm{~mole} \%$ in benzimidazole at each $\mathrm{pH}$ value can be explained by the existence of longer sequences of benzimidazole groups which may have substantial concentrations of anionic benzimidazole binding sites. That the polymers with high concentrations of benzimidazole have the ability to attract the substrate, an effect which was desired, but do not have the ability to induce esterolysis, could possibly be caused by internal association of the pendant benzimidazole groups, thus affecting the overall conformation of the polymer molecule in solution and subsequently removing benzimidazole groups from active participation in esterolysis.

As previously observed $(2,3)$, the strong dependence of the catalytic activity on the monomeric sequences along the copolymer chain could indicate that ion-pair formation 
is involved between the pendant carboxylates and the quaternary amine group in the positively charged substrates. In order to determine whether this ion-pair formation is selective, the effects of both increased substrate and increased copolymer concentration on the rates of solvolyses of 3-acetoxy- $N$-trimethylanilinium iodide $\left(\mathrm{S}_{2}{ }^{+}\right)$were examined over a wide range of concentrations at an ionic strength of 0.02 and $\mathrm{pH}$ 9.9. It was anticipated that saturation phenomena would be observed in both cases if the ion-pair formation is selective (7-9). Linear dependencies of the rates on the concentration of the copolymer and of the substrate were observed in each case (Table 3 and Fig. 6). These results do not necessarily exclude the possibility of ion-pair formation,

TABLE $3^{a}$

Attempted Observation of the Saturation Phenomena

\begin{tabular}{cccc}
\hline $\begin{array}{c}\mathrm{S}_{2}^{+b} \\
M \times 10^{5}\end{array}$ & $\begin{array}{c}\left(V_{i}-V_{i}{ }^{0}\right) \times 10^{8 c} \\
(\text { moles/liter min })\end{array}$ & $\begin{array}{c}\text { Copolymer } \\
M \times 10^{4}\end{array}$ & $\begin{array}{c}K_{\text {obs }} \times 10^{4} \\
\text { min }^{-1}\end{array}$ \\
\hline 5.16 & 4.30 & 2.72 & 5.3 \\
10.00 & 8.50 & 7.50 & 15.3 \\
15.03 & 11.80 & 10.00 & 18.6 \\
20.25 & 16.35 & 12.50 & 23.6 \\
\hline
\end{tabular}

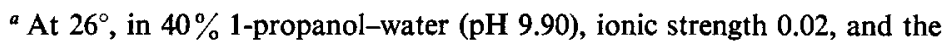
composition of copolymer: $51.4 \mathrm{~mole} \%$ in benzimidazole.

${ }^{b}$ Copolymer concentration: $5.26 \times 10^{-5} M$.

c $V_{i}$ measured initial rate of reaction in the presence of the copolymer, $V_{i}{ }^{0}$ : initial rate of reaction in the absence of the copolymer.

"Initial substrate concentration: $5.06 \times 10^{-5} \mathrm{M}$.

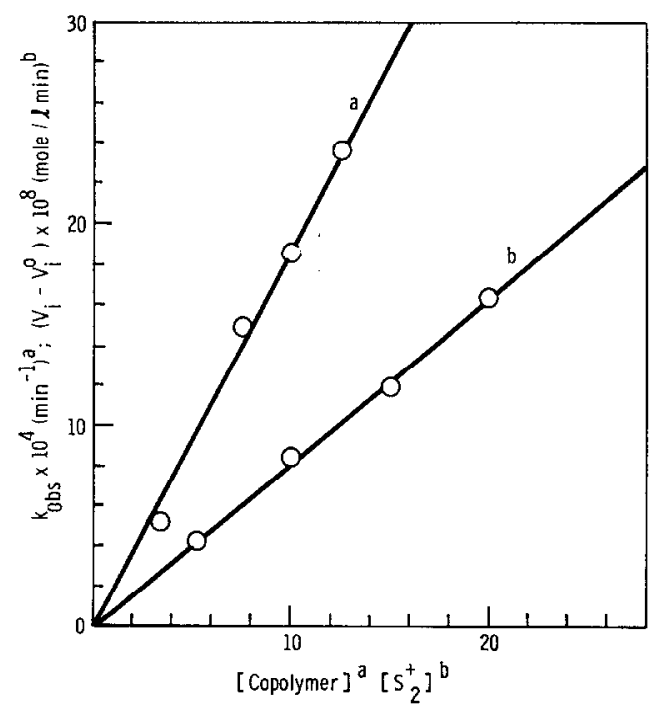

FIG. 6. Plots of $k_{\mathrm{obs}}$ versus copolymer concentration $\left(M \times 10^{-4}\right)$ and of initial rates versus substrate $\left(S_{2}{ }^{+}\right)$concentration $\left(M \times 10^{-5}\right)$, conditions: see Table 3 . 
but suggest that the substrate is not bound selectively to the anionic sites on the polymer chain.

Since the catalytic activities of the various copolymers in the 1-propanol-water system were low due to the impossibility of obtaining homogeneous solutions with less than $40 \%$ propanol, it was decided to change the alcohol used and to see if this would change the solubility and thus the activities of the copolymers. The principal effect observed thus far has been the electrostatic interactions between substrate and catalyst. In order to induce any contributions of apolar interactions the solvent system would have to be adjusted with the proper alcohol so that the copolymers would be soluble with increasing water content. The alcohol chosen for study was methanol because a system of methanol-water containing low amounts of alcohol would be very close to a purely aqueous system and might exhibit the desired apolar interactions. Only one case has been reported for polymers containing imidazole in low methanol-water compositions (10). Therefore, it was desirable to initiate an exploratory investigation in methanol-water for esterolysis reactions catalyzed by benzimidazole containing polymers.

The solvolyses of the various positively charged esters catalyzed by the copolymers of 5(6)-vinylbenzimidazole with acrylic acid in $40 \%$ methanol-water are summarized in Table 4 and Figs. 7 and 9.

TABLE $4^{a}$

Catalytic Rate Constants of Benzimidazole-Acrylic Acid Copolymers with Positively Charged Long Aliphatic Chain Substrates $k_{\text {cat }}$ (liters/mole min)

\begin{tabular}{ccrrr}
\hline pH & Substrate & CP-35 & CP-51 & CP-66 \\
\hline \multirow{2}{*}{9.90} & $\mathrm{~S}_{2}{ }^{+}$ & 150.6 & -54.0 & 39.7 \\
& $\mathrm{~S}_{\mathbf{}^{+}}{ }^{+}$ & 84.5 & -52.9 & 6.4 \\
& $\mathrm{~S}_{12}{ }^{+}$ & 74.1 & -1.0 & 44.4 \\
& $\mathrm{~S}_{\mathbf{1 8}}{ }^{+}$ & 130.4 & +458.7 & 601.7 \\
9.00 & $\mathrm{~S}_{2}{ }^{+}$ & 3.7 & 3.2 & 28.1 \\
& $\mathrm{~S}_{7}{ }^{+}$ & 6.9 & 5.5 & 12.1 \\
& $\mathrm{~S}_{12}{ }^{+}$ & 4.5 & 10.9 & 14.4 \\
& $\mathrm{~S}_{18}{ }^{+}$ & 85.5 & 90.5 & 335.6 \\
& $\mathrm{~S}_{2}{ }^{+}$ & 0.99 & 1.6 & - \\
& $\mathrm{S}_{7}{ }^{+}$ & 1.8 & 0.2 & - \\
& $\mathrm{S}_{12}{ }^{+}$ & 0.6 & 2.1 & - \\
& $\mathrm{S}_{18}{ }^{+}$ & 6.9 & - & - \\
\hline
\end{tabular}

${ }^{a} 40 \% \mathrm{MeOH} / \mathrm{H}_{2} \mathrm{O} ;$ [cat $]=5.0 \times 10^{-4} M ;$ [sub] $=5.0 \times 10^{-5} M ; \mu=0.02 ; T=26^{\circ} \mathrm{C}$.

The catalytic activities of the copolymers having different compositions followed bell-shaped curves showing minima in the composition range of 45 to $55 \mathrm{~mole} \%$ in benzimidazole at an ionic strength of 0.02 and a pH of 9.9 (Fig. 7). In general, with an increase in the size of the substrate we get increased rates of hydrolysis with the values for $\mathrm{S}_{18}{ }^{+}$completely out of the range of those represented in Fig. 7. The very high 


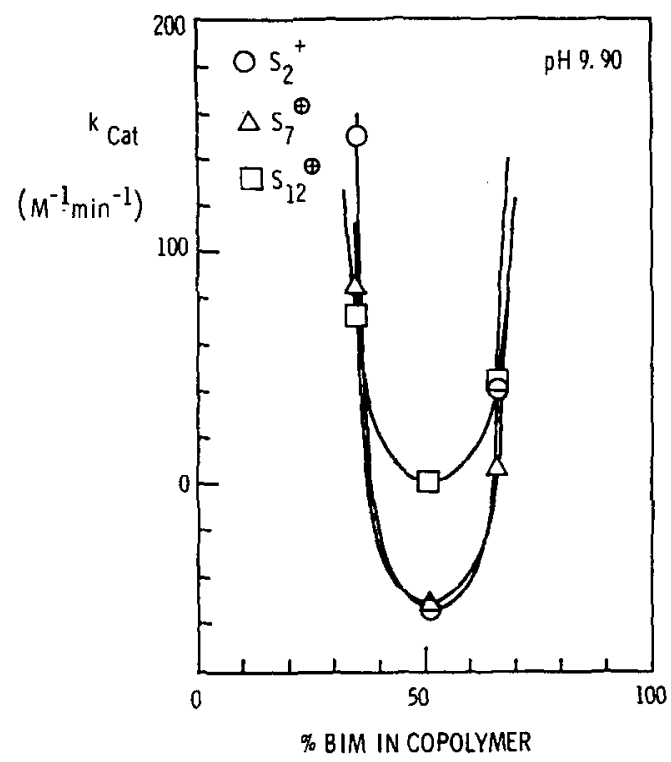

FIG. 7. Effects of copolymer composition on the catalytic rate constants for the benzimidazoleacrylic acid copolymer catalyzed solvolyses of the long chain positively charged substrates. $40 \%$ $\mathrm{MeOH} / \mathrm{H}_{2} \mathrm{O} ; \mu=0.02$.

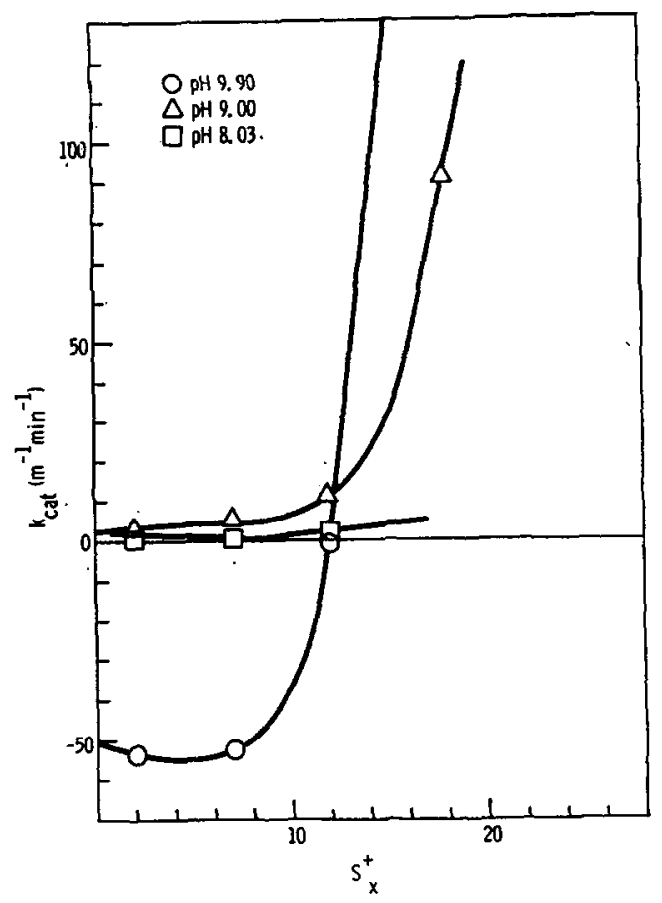

FIG. 8. Effect of varying chain length of the positively charged esters on the catalytic rate constant for the benzimidazole-acrylic acid copolymer ( $51 \mathrm{~mole} \% \mathrm{Blm}$ ) catalyzed solvolyses at various $\mathrm{pH}$. $40 \% \mathrm{MeOH} / \mathrm{H}_{2} \mathrm{O} ; \mu=0.02$. 
catalytic rate constants for $\mathrm{S}_{18}{ }^{+}$is an indication that apolar effects are operating in this system. The reason for the minimum in the composition range of 45 to $55 \mathrm{~mole} \%$ in benzimidazole is not readily apparent. The conformation of the copolymers in this range may be such that strong binding occurs for smaller substrates and catalysis does not appear until a certain chain length is exceeded. This is apparent from the data in Table 4 for CP-51 at pH 9.90 and is graphically illustrated in Fig. 8. This effect is even more dramatically observed in Fig. 9 where the data for the esterolysis at $\mathrm{pH} 9.0$ are represented.

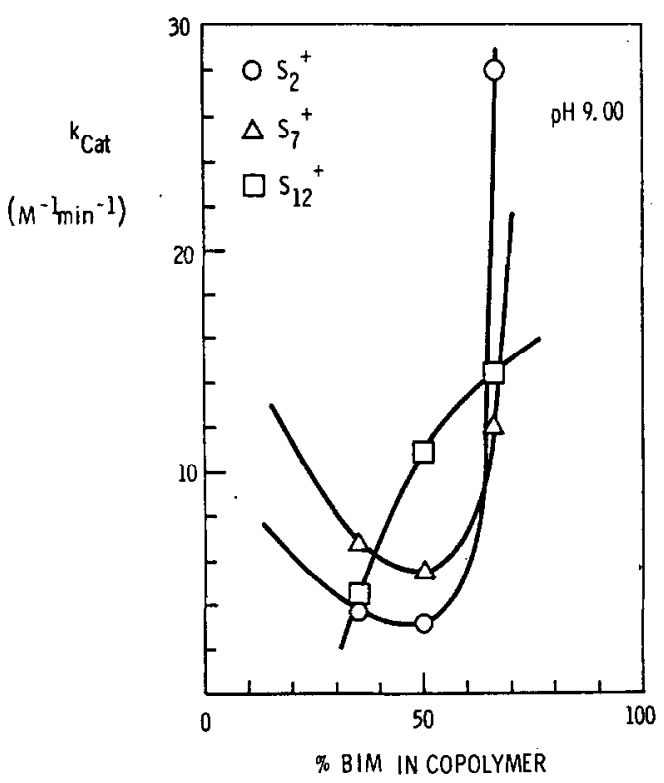

Fig. 9. Effects of copolymer composition on the catalytic rate constants for the benzimidazoleacrylic acid copolymer catalyzed solvolyses of the long chain positively charged substrates. $40 \%$ $\mathrm{MeOH} / \mathrm{H}_{2} \mathrm{O} ; \mu=0.02$.

The results of the esterolysis reactions in $40 \%$ methanol-water show that increasing the benzimidazole content in the copolymer increases the catalytic activity. This is an exact inverse to the results found in $40 \% 1$-propanol-water. Poly[5(6)-vinylbenzimidazole] was not studied in this system because of its insolubility.

Changing the solvent system has had a dramatic effect on the catalytic activities of the copolymers. The catalytic rate constants are at least 100 times larger in $40 \%$ methanol-water than in $\mathbf{4 0} \%$ 1-propanol-water, and the consequences of varying the mole $\%$ of benzimidazole in the copolymers are completely reversed. The very large catalytic rate constants for the longer chained substrates suggest that apolar interactions are now occurring.

Further, the solvolyses of the same substrates catalyzed by the various copolymers were examined in $30 \%$ methanol-water and the results summarized in Table 5 and in Figs. 10 and 11.

The results are identical to those obtained in the $40 \%$ methanol-water system but the effects are more pronounced. Increasing the size of the substrate causes an increase 
TABLE $5^{a}$

Catalytic Rate Constants of Benzimidazole-Acrylic Acid Copolymers with Positively Charged Long Aliphatic Chain Substrates $k_{\text {cat }}$ (liters/mole min)

\begin{tabular}{rrrrr}
\hline $\mathrm{pH}$ & Substrate & $\mathrm{CP}-35$ & $\mathrm{CP}-51$ & $\mathrm{CP}-66$ \\
\hline \multirow{2}{*}{9.90} & $\mathrm{~S}_{2}{ }^{+}$ & 101.1 & -149.2 & 68.8 \\
& $\mathrm{~S}_{7}{ }^{+}$ & 20.3 & -34.0 & 44.3 \\
& $\mathrm{~S}_{12}{ }^{+}$ & 3.8 & +79.0 & 139.0 \\
& $\mathrm{~S}_{18}{ }^{+}$ & 192.3 & +30.6 & - \\
9.00 & $\mathrm{~S}_{2}{ }^{+}$ & 2.5 & -17.0 & 6.9 \\
& $\mathrm{~S}_{7}{ }^{+}$ & 2.5 & -2.2 & 6.5 \\
& $\mathrm{~S}_{12}{ }^{+}$ & 10.5 & 27.3 & 43.7 \\
& $\mathrm{~S}_{18}{ }^{+}$ & 56.1 & 71.9 & - \\
& $\mathrm{S}_{2}{ }^{+}$ & 2.6 & -2.1 & - \\
& $\mathrm{S}_{7}{ }^{+}$ & 0.98 & 1.1 & - \\
& $\mathrm{S}_{12}{ }^{+}$ & 3.1 & - & - \\
& $\mathrm{S}_{18}{ }^{+}$ & -2.4 & - & - \\
\hline
\end{tabular}

${ }^{a} 30 \% \mathrm{MeOH} / \mathrm{H}_{2} \mathrm{O} ;$ [cat $]=5.0 \times 10^{-4} M ;$ [sub] $=5.0 \times 10^{-5} M ; \mu=0.02 ; T=26^{\circ} \mathrm{C}$.

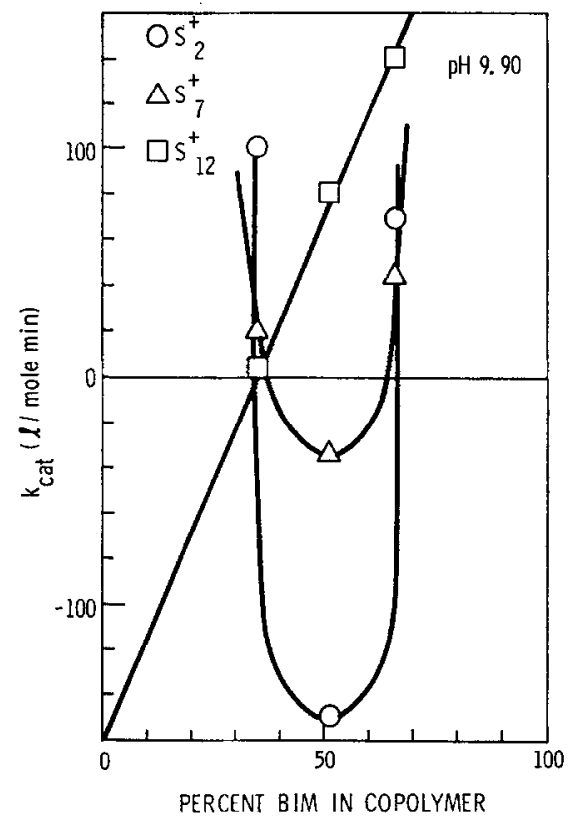

FIG. 10. Effects of copolymer composition on the catalytic rate constants for the benzimidazoleacrylic acid copolymer catalyzed solvolyses of the long chain positively charged substrates. $30 \%$ $\mathrm{MeOH} / \mathrm{H}_{2} \mathrm{O} ; \mu=0.02$.

in the catalytic ability of the various copolymers. This same effect appeared in the $40 \%$ methanol-water system but, as Figs. 10 and 11 show, is more evident in $30 \%$ methanol-water, with a change from a bell-shaped curve to a linear relationship of 
$k_{\text {cat }}$ with variation in the substrate chain length. Again, due to the large values for the solvolyses of $\mathrm{S}_{18}{ }^{+}$by the copolymers, the effects of apolar interactions appear.

Changing the composition of the solvent system from 1-propanol-water to methanolwater resulted in the appearance of apolar interactions, but also produced a more complicated effect of the mole $\%$ benzimidazole content in the copolymers on the catalytic activity. The methanol-water system is very close to a completely aqueous system and therefore the increased catalytic activity may be due to an increase in the solute-solute interactions.

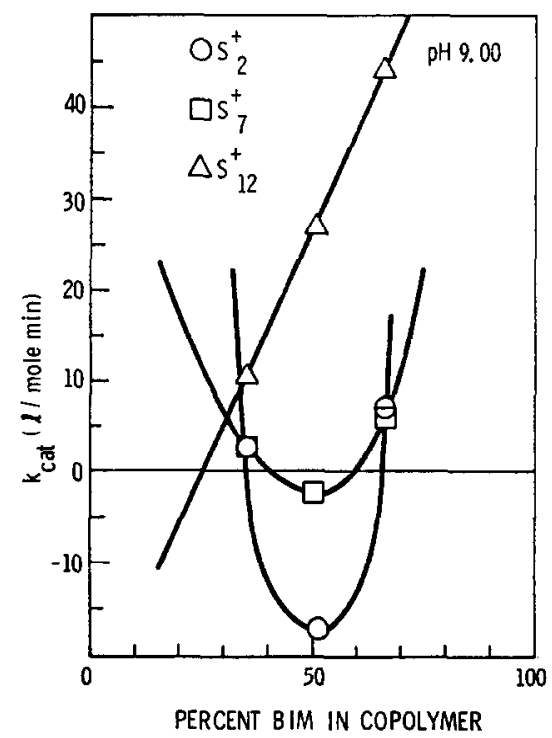

FIG. 11. Effects of copolymer composition on the catalytic rate constants for the benzimidazoleacrylic acid copolymer catalyzed solvolyses of the long chain positively charged substrates. $30 \%$ $\mathrm{MeOH} / \mathrm{H}_{2} \mathrm{O} ; \mu=0.02$.

Decreasing the methanol content in the solvent system led to a clearer representation of the effect of increasing chain length in the substrate. If apolar effects are operating efficiently we would expect an increase in $k_{\text {cat }}$ with increasing water content. This effect was not observed and may be due to difficulties in solubility. An example of this is the insolubility of poly-4(6)-vinylbenzimidazole in all methanol-water systems, as well as the decreasing solubility of the copolymers with high benzimidazole content as the percentage methanol is decreased.

In summary, the magnitudes of the second-order catalytic rate constants vary, depending on the characteristics of the catalysts, the structures of the substrates, and the composition of the solvent systems. In the buffered $40 \% 1$-propanol-water system, poly[5(6)-vinylbenzimidazole] was a poorer catalyst than benzimidazole in the hydrolysis of various long aliphatic chained positively charged esters. In this system only at high $\mathrm{pH}$ values was any activity evident. The polymer was $50 \%$ less efficient than benzimidazole for $\mathrm{S}_{2}{ }^{+}$and $\sim 90 \%$ less efficient for the longer chained substrates. The polymer exhibits very strong electrostatic interactions but the catalytic activity is 
suppressed. Since a substantial portion of the polymer was ionized to anionic benzimidazole groups, we may have strong interactions between the positively charged substrates and these groups, thus removing them from participation as a general base for hydrolysis. The hydrolysis which does occur is due to the slow nucleophilic attack of neutral species.

In the same solvent system the catalytic activities of the copolymers having different compositions followed bell-shaped curves showing maxima in the composition range of 45 to $55 \mathrm{~mole} \%$ in benzimidazole. The copolymers favored the smallest positively charged substrate with essentially very little change for the larger substrates. The high catalytic activities of these copolymers most probably is due to isolated, neutral benzimidazole sequences and suggests that bifunctional catalysis by pendant benzimidazole and carboxylate groups could occur within this sequence. One of the carboxylates might act as a binding site for the positively charged substrates, and the other might cooperate with benzimidazole in the catalytic reaction $(2,3)$. The decrease in catalytic activity with increasing chain length of the substrate may be due to steric interactions of this bifunctional catalysis. Although the detailed mechanism is not fully understood, the interaction of benzimidazole and carboxylate groups could be represented as the following:
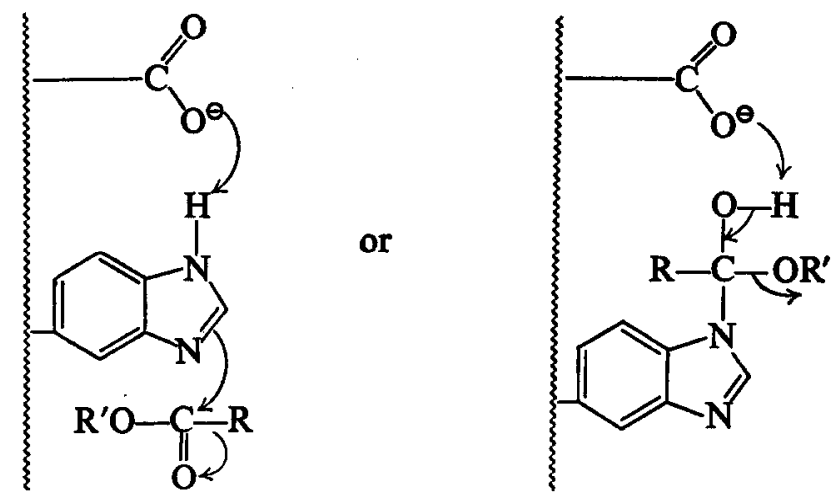

In the buffered $40 \%$ methanol-water system the catalytic activities of the copolymers having different compositions followed bell-shaped curves showing minima in the composition range of 45 to $55 \mathrm{~mole} \%$ in benzimidazole. These copolymers showed an increase in catalytic activity with an increase in the size of the substrate. The catalytic activity of the copolymers also increases with increasing content of benzimidazole in the copolymer. This indicates that the solvent system, which is approaching a purely aqueous system, affects the bifunctional catalysis which occurred in the other solvent system. The importance of the electrostatic interactions decreases and that of the apolar interactions increases. This can be shown by the data which (a) show an increase in activity with increasing chain length, and (b) show an increase in activity with increasing benzimidazole content.

In the buffered $30 \%$ methanol-water system the results are identical to those in the $40 \%$ methanol-water system but the effects are more noticeable. In these solvent systems the small positively charged species are tightly bound by electrostatic forces, 
thus suppressing the catalytic activity of the benzimidazole groups. Larger substrates, which are catalyzed by the copolymers, are not as tightly bound and bifunctional catalysis can occur; but more importantly, the high rates of catalysis show that secondary apolar forces are now appearing.

In conclusion, differences in the esterolytic catalyses between monomeric and polymeric benzimidazoles were apparent. Bifunctional interactions of pendant neutral benzimidazoles, neutral and anionic benzimidazoles, and neutral benzimidazoles and carboxylates along vinyl polymers are necessary for polymeric benzimidazoles to have significant activities.

\section{EXPERIMENTAL METHODS}

Poly[5(6)-vinylbenzimidazole] was prepared as previously described (5).

\section{Copolymerization of 5(6)-Vinylbenzimidazole with Acrylic Acid}

Various molar ratios of 5(6)-vinylbenzimidazole and acrylic acid, freshly distilled from cuprous chloride, were dissolved with azobisisobutyronitrile (AIBN) $(0.02 \mathrm{~g})$ in $5 \mathrm{ml}$ of absolute methanol in polymerization tubes. The tubes were frozen in liquid nitrogen and evacuated three times and then sealed under vacuum.

The polymerizations were carried out in a constant temperature bath at $75^{\circ} \mathrm{C}$ with stirring for proper periods. The formed copolymers precipitated from solution during the polymerizations. These solutions were poured into large excesses of absolute diethyl ether and the precipitated copolymers were collected by filtration and dried overnight at $40^{\circ} \mathrm{C}$ under vacuum. The conversion of each copolymerization was calculated from the weight of the dried samples.

The copolymers were further purified by extenisive dialysis. For the copolymer containing $35 \mathrm{~mole} \%$ of benzimidazole, the dried sample was dissolved in $3 \%$ aqueous ammonium hydroxide, filtered, and then placed in a dialysis bag. For the copolymers containing larger percentages of benzimidazole, the dried samples were dissolved in $3 \%$ potassium hydroxide, filtered; and then placed in dialysis bags. As the content of benzimidazole exceeds 45 mole \% potassium hydroxide was necessary because the ammonium hydroxide reacts with the copolymers to form salts or some sort of complexes leading to green amorphous solids which are very difficult to completely purify. The dialyses were performed for 10 days with stirring in deionized water which was changed two or three times a day. The solutions were then concentrated and freezedried. All the copolymers precipitated during dialyses.

Copolymer compositions were calculated from the nitrogen contents in the copolymers.

Anal. Found: N, 10.17 (35.4 mole \%), 13.195 (51.4 mole \%), 15.46 (66.1 mole \%), where the compositions of copolymers in benzimidazole are shown in parentheses.

\section{Substrates}

The substrates 3-acetoxy- $N$-trimethylanilinium iodide $\left(\mathrm{S}_{2}{ }^{+}\right)$, 3-heptanoyloxy- $N$ trimethylanilinium iodide $\left(\mathrm{S}_{7}{ }^{+}\right)$, 3-dodecanoyloxy- $N$-trimethylanilinium iodide $\left(\mathrm{S}_{12}{ }^{+}\right)$ and 3-octadecanoyloxy- $N$-trimethylanilinium iodide $\left(\mathrm{S}_{18}{ }^{+}\right)$were kindly supplied by 
Dr. P.-H. Vandewyer. The synthesis of 3-acetoxy- $N$-trimethylanilinium iodide $\left(\mathrm{S}_{2}{ }^{+}\right)$ has previously been reported $(11,12)$. The syntheses of the remaining substrates were performed by reacting $m$-diethylaminophenol with an acid anhydride or an acid chloride followed by quaternation of the resulting ester with methyl iodide.

\section{3-Haptanoyloxy-N-Trimethylanilinium Iodide $\left(\mathrm{S}_{7}{ }^{+}\right)$}

$m$-Dimethylaminophenol ( $13.7 \mathrm{~g}$; $0.1 \mathrm{~mole})$ was dissolved in $200 \mathrm{ml}$ of anhydrous diethyl ether. Triethylamine $(12.1 \mathrm{~g} ; 0.12 \mathrm{~mole})$ was added and finally $(16.3 \mathrm{~g} ; 0.11$ mole) heptanoylchloride was added to the solution while stirring. After $30 \mathrm{~min}$ the hydrochloride salt was filtered and the ether solution was taken to dryness leaving an oily residue $(98.2 \%$ crude yield $)$.

The oil was dissolved in $100 \mathrm{ml}$ of benzene and methyl iodide ( $22.7 \mathrm{~g}$; 0.16 mole) was added. This mixture was allowed to stand for $90 \mathrm{hr}$ at room temperature and the solid was filtered and recrystallized from benzene giving a soap-like product, yield, $23.2 \mathrm{~g} \mathrm{(57 \% ),} \mathrm{softening} \mathrm{point,} 111-112^{\circ} \mathrm{C}$, decomposition $114.5-115.5^{\circ} \mathrm{C}$.

Anal. Calcd for $\left(\mathrm{C}_{16} \mathrm{H}_{26} \mathrm{NO}_{2} \mathrm{I}\right): \mathrm{C}, 49.11 ; \mathrm{H}, 6.70 ; \mathrm{N}, 3.58 ; \mathrm{I}, 32.43$. Found: C, 49.07; $\mathrm{H}, 6.68 ; \mathrm{N}, 3.68 ; \mathrm{I}, 32.47$.

3-Dodecanoyloxy-N-trimethylanilinium Iodide $\left(\mathrm{S}_{12}{ }^{+}\right)$and 3-Octadecanoyloxy-N-trimethylanilinium Iodide $\left(\mathrm{S}_{18}{ }^{+}\right)$

These substrates were prepared in the same way as was $\mathrm{S}_{7}{ }^{+}$and were both recrystallized from benzene. $\mathrm{S}_{12}{ }^{+}$had softening point, $118-119^{\circ} \mathrm{C}$ and decomposition 121$121.5^{\circ} \mathrm{C}$.

Anal. Calcd for $\left(\mathrm{C}_{21} \mathrm{H}_{36} \mathrm{NO}_{2} \mathrm{I}\right)$ : C, $54.66 ; \mathrm{H}, 7.86 ; \mathrm{N}, 3.04 ; \mathrm{I}, 27.50$. Found: C, 54.53; $\mathrm{H}, 7.91$; N, 3.04; I, 27.39.

$\mathrm{S}_{18}{ }^{+}$had softening point $119^{\circ} \mathrm{C}$ and decomposition $126^{\circ} \mathrm{C}$.

Anal. Calcd for $\left(\mathrm{C}_{27} \mathrm{H}_{48} \mathrm{NO}_{2} \mathrm{I}\right): \mathrm{C}, 59.44 ; \mathrm{H}, 8.87 ; \mathrm{N}, 2.57 ; \mathrm{I}, 23.26$. Found: C, 59.33; $\mathrm{H}, 8.83 ; \mathrm{N}, 2.58 ; \mathrm{I}, 23.26$.

Titrations were performed as previously described (5).

Benzimidazole is an ampholyte having two dissociation constants [Eq. (1)] where $\mathrm{p} K_{1}$ and $\mathrm{p} K_{2}$ are reported to be 5.48 and 12.0 to $12.5(13)$, respectively, at $25^{\circ} \mathrm{C}$ in

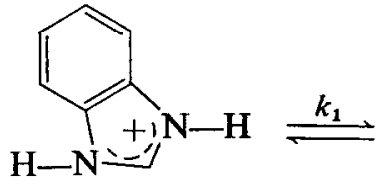

$\alpha_{0}$

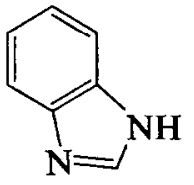

$\alpha_{1}$

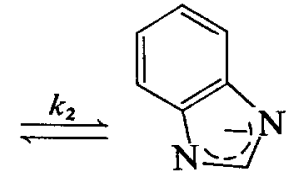

$\alpha_{2}$

water. It has been assumed that the protonated form will have no catalytic activity (14) and that the neutral form and the anionic form will each contribute to the catalytic rate. It is therefore necessary to know the state of ionization of the catalyst in order to facilitate an interpretation of the reaction kinetics.

The benzimidazole-acrylic acid copolymers are polyampholytes. For such copolymers, both spectrophotometric $(15)$ and potentiometric titrations $(16,17)$ have been employed to determine the degrees of ionization of the pendant groups. 
The titrations were carried out potentiometrically under conditions similar to those used for the kinetic studies, i.e., in the desired alcohol-water compositions at $26^{\circ} \mathrm{C}$ and an approximate ionic strength of 0.02 . The reliability of the method of titration was ascertained for benzimidazole. Employing the differential titration method (18), $\mathrm{p} K_{1}$ values obtained for benzimidazole were 5.15 in $40 \% 1$-propanol-water, 5.08 in $40 \%$ methanol-water and 5.38 in $30 \%$ methanol-water. These values are consistent with those previously reported, i.e., 5.48 (water) and 4.98 (50\% ethanol-water).(13) and $5.16(30 \% 1$-propanol-water) for benzimidazole (19).

In the titrations of the copolymers, however, some difficulties were encountered. The copolymers precipitated from solution in the region of their isoelectric points during the titrations. At the isoelectric points, the overall electrostatic field potential around the copolymers disappears and then alters its sign if the titration is continued. As a consequence, polyampholytes become least soluble and a drift of $\mathrm{pH}$ occurs (15-17).

In the course of titration of a polyelectrolyte, the surroundings of every dissociable, pendant group vary continuously and a range of dissociation of these groups becomes wider than those of simple monomeric electrolytes. For a polyampholyte, the surroundings of each pendant group becomes more complex. The inflection point between the dissociation of the benzimidazolium ions and the carboxyl groups on the polymer chain for the copolymer containing 66 mole \% BIm was not clearly observed. The titration ranges, therefore, were estimated by dividing the total range of dissociation into two ranges each of which had a width proportional to the copolymer composition.

$\mathrm{pH}$ versus $\alpha_{1}$ relationships were found to follow the modified Henderson equation [Eq. (2), Fig. 12] (20). The apparent dissociation constants, $\mathrm{p} K_{1}$, were evaluated

$$
\mathrm{pH}=\mathrm{p} K_{1}-n \log \left(\frac{1-\alpha_{1}}{\alpha_{1}}\right)
$$

graphically at the points when $\alpha_{1}=0.5$. The results are summarized in Table 6 .

The dissociation of neutral, pendant benzimidazole to its anionic form could not be detected in these titrations.

Kinetic measurements were performed as previously described (5). The solvent, $40 \%$ 1-propanol-water, was used for every kinetic run. The solutions were buffered with tris(hydroxymethyl)aminomethane (Tris) $(0.02 M)$-hydrochloric acid at $\mathrm{pH} 7-9$ and with 3-( $N, N$-dimethylamino)propanol $(0.02 M)$-hydrochloric acid at pH above 9. The ionic strength was adjusted by addition of potassium chloride. The rates of solvolyses were determined by following the increase in the absorbance of the released phenols at $400 \mathrm{~nm}$. All the obtained data followed first-order kinetics. The pseudofirst-order rate constants $k_{\text {measd }}$ (with catalyst), $k_{\text {blank }}$ (without catalyst), were treated by the expressions $k_{\text {obsd }}=k_{\text {measd }}-k_{\text {blank }}$ and $k_{\text {cat }}=k_{\text {obsd }} /$ [catalyst] wherc [catalyst] is the molar concentration of benzimidazole functions.

For kinetic measurements in the presence of excess substrate the following procedure was utilized. A solution of the copolymer was prepared in $35.4 \% 1$-propanol-water $\left(5.0 \times 10^{-5} M\right)$ buffered with $0.02 M$ Tris at $\mathrm{pH} 9.9$ and $\mu=0.02$. To $3.0 \mathrm{ml}$ of this solution in a quartz cell was added $0.2 \mathrm{ml}$ of freshly prepared substrate solution (5.0 to $20.0 \times 10^{-5} \mathrm{M} ; 100 \% 1$-propanol) (final composition $40 \% 1$-propanol-water). The initial rates were determined at the wavelength $293 \mathrm{~nm}$ and at $26^{\circ} \mathrm{C}$ by using a Beckman 


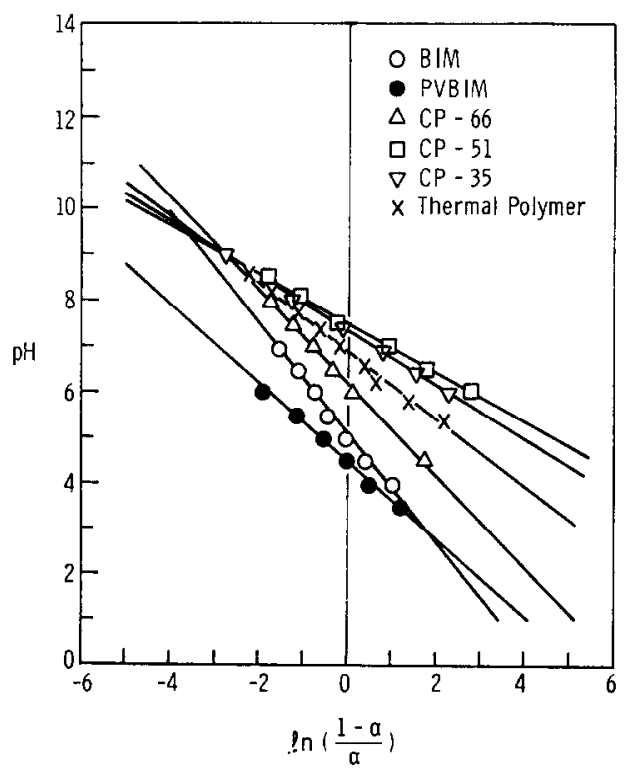

Fig. 12. Plots of pH versus $\ln \left[\left(1-\alpha_{1}\right) / \alpha_{1}\right]$ for the benzimidazole-acrylic acid copolymers; $40 \%$ $n \mathrm{PrOH} / \mathrm{H}_{2} \mathrm{O}$.

DU spectrophotometer. In 10 min approximately $10 \%$ conversion was reached. The plots of optical density vs time were linear up to ca. $5 \%$ conversion. The initial rates $\left(V_{i}\right)$ were calculated from the slopes of the linear portions of these plots. The initial rates due to spontaneous hydrolyses, $\left(V_{0}\right)$, were determined in the same manner as mentioned above, but without the copolymer.

TABLE $6^{a}$

Results of Potentiometric Titrations of Pendant Benzimidazolium Ions in the COPOLYMERS OF 5(6)-VINYLBENZIMIDAZOLE WITH ACRYLIC ACID

\begin{tabular}{ccccc}
\hline & $\begin{array}{c}\text { Copolymer } \\
\text { composition } \\
\text { Solvent }\end{array}$ & & & \\
\hline $40 \% n \mathrm{PrOH} / \mathrm{H}_{2} \mathrm{O}$ & $100^{c}$ & 4.50 & 1.99 & - \\
& $\begin{array}{c}\text { Ppt. }^{b} \\
\text { range }\end{array}$ \\
\hline & 51 & 6.90 & 1.71 & - \\
& 35 & 7.50 & 2.26 & $5.2 \rightarrow 7.5$ \\
$40 \% \mathrm{MeOH} / \mathrm{H}_{2} \mathrm{O}$ & 66 & 7.40 & 1.37 & $3.9 \rightarrow 7.2$ \\
& 51 & 5.50 & 1.92 & $4.6 \rightarrow 7.2$ \\
$30 \% \mathrm{MeOH} / \mathrm{H}_{2} \mathrm{O}$ & 66 & 7.45 & 1.38 & $4.1 \rightarrow 7.6$ \\
& 51 & 6.65 & 2.26 & $4.5 \rightarrow 8.4$ \\
& & 7.50 & 1.79 & $4.1 \rightarrow 8.0$ \\
\hline
\end{tabular}

${ }^{a}$ At $26^{\circ}$, ionic strength $=0.02$.

${ }^{b}$ The range of $\mathrm{pH}$ where precipitation was observed.

'Poly[5(6)-vinylbenzimidazole]. 


\section{ACKNOWLEDGMENT}

The authors are grateful for financial support from the National Institutes of Health under Grant No. 2 RO1 GM 15256, and to the Macromolecular Research Center of The University of Michigan. We also thank Professors J. E. Mark and D. T. Longone for their helpful discussions.

\section{REFERENCES}

1. C. G. Overberger, R. Sitaramaiah, T. St. Pierre, and S. Yaroslavsky, J. Amer. Chem. Soc. $87,3270(1965)$.

2. C. G. OVERBERGER AND H. MAKI, Macromolecules 3, 214 (1970).

3. C. G. OVERBERger AND H. MAKI, Macromolecules 3, 220 (1970).

4. C. G. Overberger and J. C. Salamone, Accounts Chem. Res. 2, 217 (1969), and references cited therein.

5. C. G. Overberger and C. J. Podsiadly, Bioorganic Chem. 3, 16 (1974)

6. L. J. WeBB, "Enzyme and Metabolic Inhibitors," 3 Vols. Academic Press, New York, 1963.

7. H. Morawetz and J. A. Shafer, J. Phys. Chem. 67, 1293 (1963).

8. R. L. Letsinger and I. S. Klaus, J. Amer. Chem. Soc. 87, 3380 (1965).

9. C. G. Overberger, M. Morimoto, I. Cho, and J. C. Salamone, J. Amer. Chem. Soc. 93, 3228 (1971).

10. C. G. Overberger, T. St. Pierre, C. Yaroslavsky, and S. Yaroslavsky, J. Amer. Chem. Soc. 88, 1184 (1966).

11. R. L. Letsinger and I. Klaus, J. Amer. Chem. Soc. 87, 3380 (1965).

12. C. G. Overberger, J. C. Salamone, and S. Yaroslavsky, J. Amer. Chem. Soc. 89, 6231 (1967).

13. K. Hofman, "Imidazole and Its Derivatives." Wiley (Interscience), New York, 1953.

14. M. L. Bender and B. W. Turnquist, J. Amer. Chem. Soc. 79, 1652 (1957); T. C. Bruice And G. L. SchmiR, J. Amer. Chem. Soc. 79, 1663 (1957); and W. P. Jencks and J. Carriuolo, J. Amer. Chem. Soc. 83, 1743 (1961).

15. A. Katchalski and I. R. Miller, J. Polym. Sci. 13, 57 (1954).

16. H. L. WAGNer ANd F. A. Long, J. Phys. Colloid Chem. 55, 1512 (1951).

17. T. Alfrey and H. S. Pinner, J. Polym. Sci. 13, 533 (1954).

18. T. V. Parke and W. W. Davis, Anal. Chem. 26, 642 (1954).

19. T. St. PIERre, PhD thesis, Polytechnic Inst. of Brooklyn, 1966.

20. A. Katchalski And J. Gillis, Rec. Ton. Chim. 68, 879 (1949); Chem. Abstr. 44, 2892 (1950). 